\title{
23\% of newly diagnosed HIV cases in 2007 at Karolinska University Hospital had opportunistic infections $\mathrm{K}$ Egnell ${ }^{1}$ and V Svedhem ${ }^{* 2}$
}

Address: ${ }^{1}$ Karolinska Institut, Stockholm, Sweden and ${ }^{2}$ Karolinska University Hospital, Stockholm, Sweden

* Corresponding author

from Ninth International Congress on Drug Therapy in HIV Infection

Glasgow, UK. 9-13 November 2008

Published: 10 November 2008

Journal of the International AIDS Society 2008, I I (SuppI I):P256 doi:I0.I I86/I758-2652-I I-SI-P256

This abstract is available from: http://www.jiasociety.org/content/I I/SI/P256

(c) 2008 Egnell and Svedhem; licensee BioMed Central Ltd.

\section{Purpose of the study}

A major challenge in controlling the HIV epidemic is that a large proportion of infected individuals are unaware of their infection [1]. In Sweden this group is estimated to be $10-20 \%$ of the known HIV-infected population [2].

\section{Methods}

The patients were identified in the national databas Infcare and their medical records has been studied.

\section{Summary of results}

In 2007 almost half of newly diagnosed HIV cases (36 of 82) at Karolinska University Hospital were late testers,

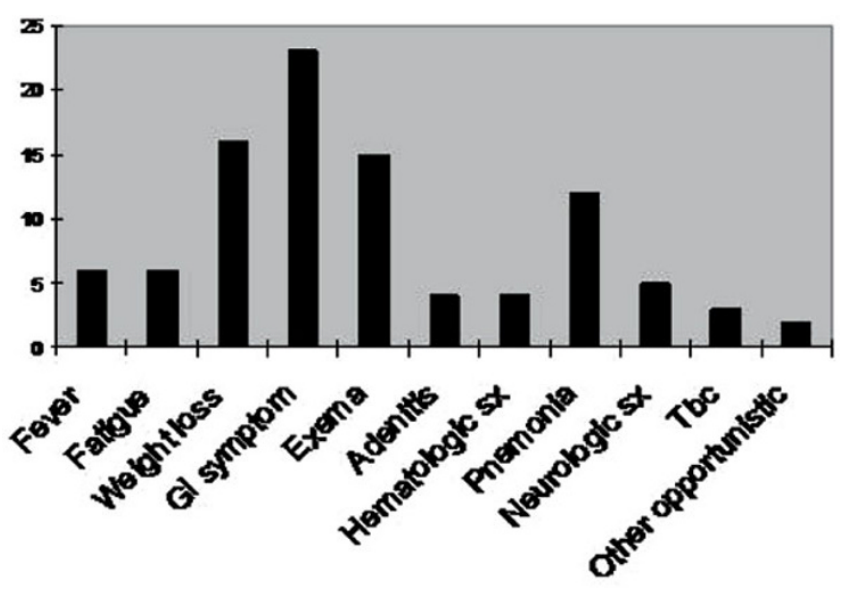

Figure I

Test-related symptoms. defined as patients with CD4 counts $<200$. In this group of late testers, immigrants with heterosexual mode of transmission $(\mathrm{n}=22)$ dominated. A smaller number of persons were injecting drug users (IDU; $\mathrm{n}=4$ ), and men having sex with men (MSM; $n=3)$. The group is found to have increased morbidity and mortality: 19 of the patients had AIDS and two of them died shortly after diagnosis. The majority of these late testers have been in contact with the health care system with symptoms months or even years before HIV testing was performed. Both symptoms at earlier contact and test-related symptoms are shown in Figure 1.

\section{Conclusion}

Identifying these symptoms, which were not recognised as HIV-related by health workers, will help us to find these patients earlier. Identifying the pathways that these patients used to get into the health care system, will tell us where to intensify HIV testing.

\section{References}

I. Coenen T, Lundgren J, Lazarus JV, Matic S: Optimal HIV testing and earlier care: the way forward in Europe. HIV Med 2008, 9(Suppl 2): I-5.

2. Blaxhult A: Infected abroad - risk factor for late HIV diagnosis. Lakartidningen [0023-7205]. Oppenheimer ar 2008, 105 (5):292. 